\title{
Clinical relevance of urate nephrolithiasis in bottlenose dolphins Tursiops truncatus
}

\author{
Stephanie Venn-Watson ${ }^{1, *}$, Cynthia R. Smith ${ }^{1}$, Shawn Johnson ${ }^{2}$, Risa Daniels ${ }^{1}$, \\ Forrest Townsend ${ }^{3}$
}

${ }^{1}$ National Marine Mammal Foundation, San Diego, California 92106, USA

${ }^{2}$ US Navy Marine Mammal Program, San Diego, California 92152, USA

${ }^{3}$ Bayside Hospital for Animals, Fort Walton Beach, Florida 32547, USA

\begin{abstract}
Few cases of nephrolithiasis (renal calculi) have been reported in bottlenose dolphins Tursiops truncatus. A case-control study was conducted to compare ultrasonographic images and clinicopathologic serum and urine values among 14 dolphins with nephrolithiasis (mild cases: 1 to 19 nephroliths, $\mathrm{n}=8$; advanced cases: $\geq 20$ nephroliths, $\mathrm{n}=6$ ) to 6 controls over an 18 mo period. Archived nephroliths collected postmortem from 7 additional bottlenose dolphins were characterized using quantitative analysis. All advanced cases had bilateral nephroliths, and $67 \%$ had visible collecting ducts. During the study, 2 of the advanced cases developed hydronephrosis, and 1 of these cases had ureteral obstruction due to a nephrolith. Compared to controls, cases (mild and advanced) were significantly more likely to have anemia (hematocrit $[\mathrm{HCT}]<38 \%$ ), high blood urea nitrogen $\left(>59 \mathrm{mg} \mathrm{dl}^{-1}\right)$, high creatinine $\left(>1.9 \mathrm{mg} \mathrm{dl}^{-1}\right)$, and low estimated glomerular filtration rate $(<150 \mathrm{ml}$ $\mathrm{min}^{-1} 2.78 \mathrm{~m}^{-2}$ ). Advanced-case urine samples were more likely to have erythrocytes, occult blood, and lower $\mathrm{pH}$ compared to mild cases and controls. Mean serum uric acid among all study groups was low $\left(0.15\right.$ to $\left.0.27 \mathrm{mg} \mathrm{dl}^{-1}\right)$. Urinary uric acid concentrations were highest among mild cases (272 $\mathrm{mg} \mathrm{g}^{-1}$ creatinine), but advanced cases had levels lower than that of controls (40 and $127 \mathrm{mg} \mathrm{g}^{-1}$ creatinine, respectively). All nephroliths were characterized as $100 \%$ ammonium acid urate. We conclude that nephrolithiasis is clinically relevant in dolphins and can decrease renal function and HCT. The presence of nephrolithiasis, presumably ammonium acid urate nephrolithiasis, in the face of low serum uric and relatively low urinary uric acid in advanced cases may indicate a metabolic syndrome similar to that reported in humans.
\end{abstract}

KEY WORDS: Nephrolithiasis $\cdot$ Ammonium acid urate $\cdot$ Bottlenose dolphin $\cdot$ Tursiops truncatus Resale or republication not permitted without written consent of the publisher

\section{INTRODUCTION}

Nephrolithiasis (the presence of renal calculi) has been reported in many animal species, including cats, dogs, humans, and river otters, and may lead to ureteral hypertrophy, obstruction, physical renal tissue damage, hydronephrosis, and renal failure (Osborne et al. 1995, Grove et al. 2003, Moe 2006). Nephrolithiasis has been reported in few marine mammals, including a northern elephant seal, a harbor seal, a California sea lion, and 2 West Indian manatees (Stroud 1979, Dennison et al. 2007, Keller et al. 2008). We previously reported a case of end-stage renal disease associated with urate nephrolithiasis in an adult male bottlenose dolphin Tursiops truncatus (Venn-Watson et al. 2008). While postmortem cases of nephrolithiasis have been reported in marine mammals and are known to exist in the Navy Marine Mammal Program (MMP) dolphin population, the clinical significance of underlying nephrolithiasis in dolphin populations has not been assessed. We conducted a case-control study at the MMP comparing 14 dolphins with ultrasonographic evidence of nephrolithiasis to 6 controls, given the null hypothesis that there would be no significant differences in mean clinicopathologic values, estimated glomerular filtration rate (eGFR), and clinical urine 
values when comparing dolphins with or without evidence of nephroliths. Additionally, archived nephroliths previously collected postmortem from dolphins at the MMP and other facilities were submitted for chemical analysis.

\section{MATERIALS AND METHODS}

Animal care and use. The MMP is accredited by the Association for Assessment and Accreditation of Laboratory Animal Care International and adheres to the national standards of the United States Public Health Service Policy on the Humane Care and Use of Laboratory Animals and the Animal Welfare Act. As required by the Department of Defense, the MMP's animal care and use program is routinely reviewed by an Institutional Animal Care and Use Committee and the Department of Defense Bureau of Medicine.

Retrospective stone evaluation. Archived nephroliths collected postmortem at the MMP and other facilities during 1985 through 2009 were submitted to the Minnesota Urolith Center (University of Minnesota, College of Veterinary Medicine, St. Paul, Minnesota) for quantitative analysis using polarizing light microscopy (Ulrich et al. 1996). The reference laboratory also observed the samples for the presence of xanthine using infrared spectroscopy (Ulrich et al. 1996).

Ultrasound evaluations and study population definitions. Both kidneys from 20 dolphins were evaluated and total nephrolith counts were estimated using at least 1 renal ultrasound examination during the study period. A Voluson $i$ portable ultrasound machine with a 2 to $5 \mathrm{MHz} 4 \mathrm{D}$ transducer (RAB2-5-RS; General Electric Healthcare) was used to capture images of the kidneys. Ultrasound evaluation using B-mode with tissue harmonic imaging included (1) nephrolith identification and quantification, and (2) measurement of the collecting duct if it was visible. Collecting-duct measurements were only included if color Doppler ultrasound confirmed that the image was a collecting duct and not a vessel. To evaluate kidneys for the presence of nephroliths, cine loops of each kidney were captured in both the longitudinal and transverse planes and then reviewed with OsiriX imaging software (open source; www.osirix-viewer.com). Nephroliths were identified as hyperechoic foci within the kidney that created acoustic shadowing and were quantitated for a total nephrolith count per kidney (see Fig. 1). We did not use color or power Doppler to look for twinkling artifact as an identifier of nephroliths in our study. Nephrolith measurements were made using the transverse plane. Of the population, $6(30 \%)$ had no evidence of nephroliths, $8(40 \%)$ had 1 to 19 nephroliths, and $6(30 \%)$ had $\geq 20$ nephroliths. These categories were defined as controls, mild cases, and advanced cases, respectively. Example ultrasound images from the study population are provided to demonstrate a control, a mild case, and an advanced case (see Fig. 1). Although not included as a formal part of the present study, 3 of the advanced cases had computer tomography (CT) scans for medical-management purposes. The number of nephroliths detected by CT in those 3 animals closely matched the numbers identified by ultrasound.

Sample collection and analyses. Serum and urine samples were collected from cases and controls over 18 mo (January 2006 through June 2007). Blood samples were collected by venipuncture from either the periarterial venous rete in the caudal peduncle or a fluke blade (Dold \& Ridgway 2007). These methods for blood collection have been used by the MMP for $>30 \mathrm{yr}$, including for establishing normal reference ranges of complete blood-cell counts and serum chemistries (Venn-Watson et al. 2007). While blood collection from the periarterial venous rete has the potential for arterial or mixed arterial-venous sampling, no differences in blood values involved in the present study have demonstrated significant differences by sampling site (S. Venn-Watson, C. R. Smith, R. Daniels unpubl. data). Animals were trained to voluntarily present their tail for sampling, or behavioral conditioning was utilized to collect samples out of the water on a foam mat during a routine physical examination. Samples were collected using either a 20 or 21 gauge 1.5 inch $(3.8 \mathrm{~cm})$ Vacutainer ${ }^{\circledR}$ needle (Becton Dickinson VACUTAINER Systems) or a 21 gauge 0.75 inch $(1.9 \mathrm{~cm})$ butterfly needle attached to a Vacutainer ${ }^{\circledR}$ Holder. Blood was collected into a Vacutainer ${ }^{\circledR}$ serum separator tube (SST) or a Vacutainer ${ }^{\circledR}$ EDTA $\left(\mathrm{K}_{3}\right)$ tube for serum chemistries and complete blood counts $(\mathrm{CBC})$, respectively.

Samples were chilled for $30 \mathrm{~min}$ and centrifuged within $2 \mathrm{~h}$. Centrifugation was performed at $1006 \times g$ at $21^{\circ} \mathrm{C}$ for $10 \mathrm{~min}$. Fibrin clots were removed and serum was transferred to a $5 \mathrm{ml}$ plastic submission tube. Whole blood was submitted in EDTA Vacutainer ${ }^{\circledR}$ tubes. All samples were sent on ice via courier to Quest Diagnostic Laboratories in San Diego, California. Automated analyses were used by Quest Diagnostic Laboratories, including the Coulter ${ }^{\circledR}$ LH 1500 Series (Beckman Coulter) for hematology and the Olympus ${ }^{\circledR}$ AU600 (Olympus America) for serum chemistry analysis. Fisherbrand Dispette $2^{\circledR}$, correlating with the Westergren method, was used to determine $60 \mathrm{~min}$ erythrocyte sedimentation rates (ESR) from $1 \mathrm{ml}$ EDTA whole blood.

The following hematologic and serum biochemical variables were measured and incorporated into the retrospective study: total white blood cell count (WBC), 
hematocrit (HCT), mean corpuscular volume (MCV), mean corpuscular hemoglobin $(\mathrm{MCH})$, mean corpuscular hemoglobin concentration (MCHC), mean platelets, mean platelet volume (MPV), absolute neutrophils, absolute lymphocytes, absolute monocytes, absolute eosinophils, glucose, blood urea nitrogen (BUN), creatinine, uric acid, sodium, potassium, chloride, carbon dioxide $\left(\mathrm{CO}_{2}\right)$, total protein, globulins, iron, creatinine, and ESR. The eGFR was measured using a serumbased equation modified for bottlenose dolphins (Venn-Watson et al. 2008).

Urine samples were collected from bottlenose dolphins in $120 \mathrm{ml}$ sterile plastic specimen cups using a variety of methods, including catheterization, free catch, and manual bladder expression; the overwhelming majority of samples were acquired by free catch or manual bladder expression. Fresh samples were realiquoted into 2 sterile $15 \mathrm{ml}$ conical tubes, refrigerated, and shipped cold via same-day courier to a local reference laboratory. At the reference laboratory, Bayer reagent strips for urinalysis were used for each sample to determine $\mathrm{pH}$, color, clarity, and presence of the following analytes: glucose, ketones, occult blood, protein, bacteria, and crystals. Semi-automated reflectance reading of dipsticks was performed using the Bayer Clinitek Atlas Urine Chemistry Analyzer. Urinespecific gravity was determined by refractive index both manually with a refractometer and by the Bayer Atlas. A sulfosalicylic acid precipitation test (SSA) was used for validation of any proteinuria detected by the Bayer Atlas. Olympus reagents were used in the Olympus AU5400 to analyze quantitative protein, uric acid, and creatinine. Protein:creatinine and uric acid:creatinine ratios were calculated.

Statistical methods. Analyses were conducted using SAS version 9.2. Descriptive statistics were conducted on the study population, including mean age and time at facility, and frequencies of sex, species, and birth origin (captive-born or wild-caught). To assess for potential confounders, population descriptors were compared between mild cases, advanced cases, and control samples ( a variable labeled CASE-CONTROL) using chi-squared tests for categorical variables and general linear models for continuous variables (PROC GLM; CLASS CASE-CONTROL; MODEL AGE TIME_ AT_FACILITY =CASE-CONTROL; MEANS CASECONTROL). Comparisons of the frequencies of bilateral nephroliths and visible collecting ducts were performed using a chi-squared test (PROC FREQ; TABLES (BILATERAL COLL_DUCT) ${ }^{*}$ CASE-CONTROL/CHISQ). Mean clinicopathologic values, eGFR, and urine values were compared using a general linear model that controlled for varying numbers of samples per animal (PROC GLM; CLASS CASE-CONTROL SEX; MODEL [blood and urine variables]= AGE SEX
CASE-CONTROL; LSMEANS CASE-CONTROL). Since age and sex may have an influence on many blood variables (Venn-Watson et al. 2007), least-squares means controlling for age and sex were reported. Post hoc Scheffé's tests were conducted for intergroup comparisons. Clinicopathologic values with significant mean differences between cases and controls were further assessed for clinically relevant differences by comparing the frequencies of values that were clinically high or low using chi-squared tests. Normal clinicopathologic and eGFR values for the MMP dolphin population had been determined previously (Venn-Watson et al. 2007 , 2008). Normal urine values for healthy bottlenose dolphins in this population had not been determined previously. p-values $<0.01$ were defined as significant for all statistical tests.

\section{RESULTS}

\section{Nephrolith evaluation}

Based upon polarizing light microscopy, all archived nephroliths collected postmortem from 7 bottlenose dolphins during 1985 to 2009 were characterized as $100 \%$ ammonium acid urate in composition. While most of these archived nephroliths were collected from MMP dolphins, none of these dolphins were part of the case-control study (no 'case' dolphins died during the study).

\section{Study population}

A total of 20 bottlenose dolphins were included in the case-control study. Nine (45\%) were female, and the median age of animals at the study's mid-point was $22.7 \mathrm{yr}$ (range, 3.2 to $32.2 \mathrm{yr}$ ). Eighteen (90\%) animals were Atlantic bottlenose dolphins Tursiops truncatus truncatus, and $2(10 \%)$ were Atlantic and Pacific bottlenose dolphin hybrids $T$. truncatus truncatus/gilli. Nine $(45 \%)$ were captive-born at the MMP or one other facility, and 11 (55\%) were wild-caught from the Gulf of Mexico. Median time in custody for all 20 animals was $18 \mathrm{yr}$ (range, 0.9 to $28 \mathrm{yr}$ ). When comparing these population descriptors by case or control status, there were no significant differences (Table 1).

\section{Ultrasound findings}

The mean total number of nephroliths among mild and advanced cases was 4.8 and 31.8, respectively (Table 2). Sample ultrasound images from a control, mild case, and advanced case are provided (Fig. 1). 
Table 1. Tursiops truncatus. Comparisons of population descriptors by study group. Mild cases: 1 to 19 nephroliths, advanced cases: $\geq 20$ nephroliths

\begin{tabular}{|lcccc|}
\hline Descriptor & $\begin{array}{c}\text { Control } \\
(\mathrm{n}=6)\end{array}$ & $\begin{array}{c}\text { Mild cases } \\
(\mathrm{n}=8)\end{array}$ & $\begin{array}{c}\text { Advanced cases } \\
(\mathrm{n}=6)\end{array}$ \\
\hline Percent female & 66.7 & 37.5 & 33.3 & 0.44 \\
Percent captive born & 33.3 & 50 & 50 & 0.79 \\
Median age (yr) & 22.7 (range 4.2-26.2) & 14.7 (range 3.2-32.2) & 12.6 (range 0.7-28.4) & 0.78 \\
Median time at institution (yr) & 18.1 (range 4.2-19.3) & 11.6 (range 0-28.4) & 12.6 (range 0.7-28.4) & 0.85 \\
\hline
\end{tabular}

Table 2. Tursiops truncatus. Comparisons of ultrasound descriptors by study group. Mild cases: 1 to 19 nephroliths, advanced cases: $\geq 20$ nephroliths. na $=$ not applicable

\begin{tabular}{|lcccc|}
\hline Ultrasound descriptor & $\begin{array}{c}\text { Control } \\
(\mathrm{n}=6)\end{array}$ & $\begin{array}{c}\text { Mild cases } \\
(\mathrm{n}=8)\end{array}$ & $\begin{array}{c}\text { Advanced cases } \\
(\mathrm{n}=6)\end{array}$ \\
\hline Mean total nephroliths & 0 & 4.8 & 31.8 & $<$ \\
Mean nephrolith size $(\mathrm{cm})$ & na & 0.8 & 0.9 & 0.0001 \\
No. (\%) bilateral nephroliths & na & $4 / 8(50)$ & $6 / 6(100)$ & 0.02 \\
No. (\%) left collecting duct visualized & 0 & 0 & $3 / 6(50)$ & $<0.0001$ \\
No. (\%) right collecting duct visualized & 0 & 0 & $2 / 6(33)$ & $<0.0001$ \\
Range of size of collecting duct, if visualized $(\mathrm{cm})$ & 0 & 0 & $0.7-1.7$ & na \\
\hline
\end{tabular}
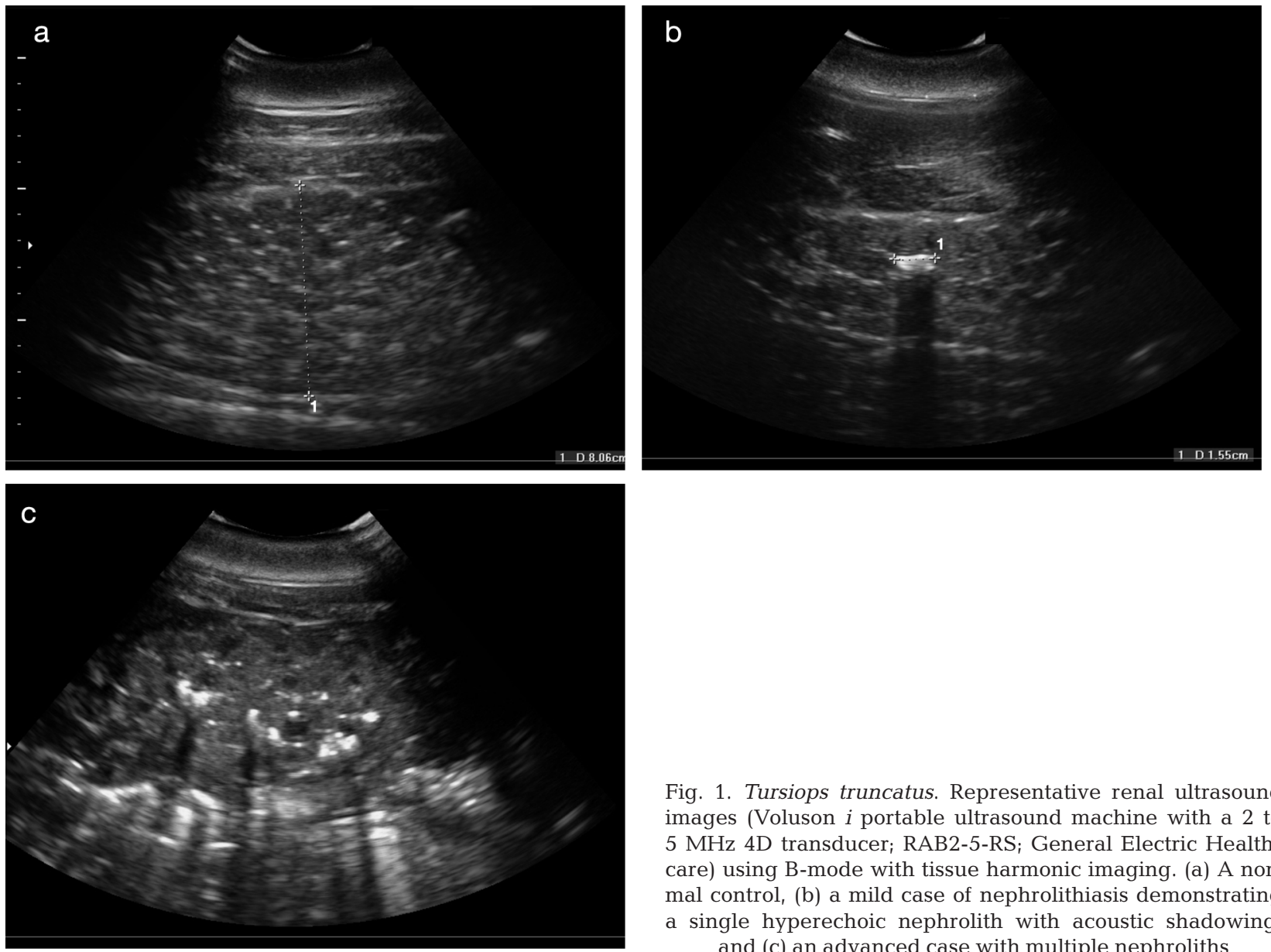

Fig. 1. Tursiops truncatus. Representative renal ultrasound images (Voluson $i$ portable ultrasound machine with a 2 to $5 \mathrm{MHz} 4 \mathrm{D}$ transducer; RAB2-5-RS; General Electric Healthcare) using B-mode with tissue harmonic imaging. (a) A normal control, (b) a mild case of nephrolithiasis demonstrating a single hyperechoic nephrolith with acoustic shadowing, and (c) an advanced case with multiple nephroliths 
There were no significant differences in mean nephrolith size when comparing mild and advanced cases $(p=0.23)$. The mean and median nephrolith sizes in mild cases were $0.8 \pm 0.4(\mathrm{SD}) \mathrm{cm}$ and $0.7 \mathrm{~cm}$ (range, 0.3 to $1.7 \mathrm{~cm}$ ), and in advanced cases were $0.9 \pm 0.4 \mathrm{~cm}$ and $0.7 \mathrm{~cm}$ (range, 0.3 to $3.5 \mathrm{~cm}$ ), respectively. Four (50\%) mild cases had bilateral nephroliths, and all $(100 \%)$ advanced cases had bilateral nephroliths. None of the controls or mild cases had confirmed visible collecting ducts. Three (50\%) advanced cases had visible collecting ducts with sizes ranging from 0.7 to $1.7 \mathrm{~cm} ; 2$ of these cases had collecting ducts visualized bilaterally (Fig. 2). During the study period, 2 of the advanced cases developed hydronephrosis visualized by ultrasound, and ureteral obstruction due to a nephrolith was confirmed in 1 of these animals by CT scan.

\section{Clinicopathologic tests and eGFR}

A summary of mean clinicopathologic values by study group is provided in Table 3. Serum BUN was significantly higher in advanced cases compared to mild cases, and in mild cases compared to controls. The same trend was detected with BUN:creatinine ratios, and there were no significant differences in mean serum creatinine among all 3 groups.

Mild cases were more likely to have lower total WBC counts and absolute neutrophils compared to advanced cases and controls. Advanced cases had significantly lower serum iron compared to mild cases and

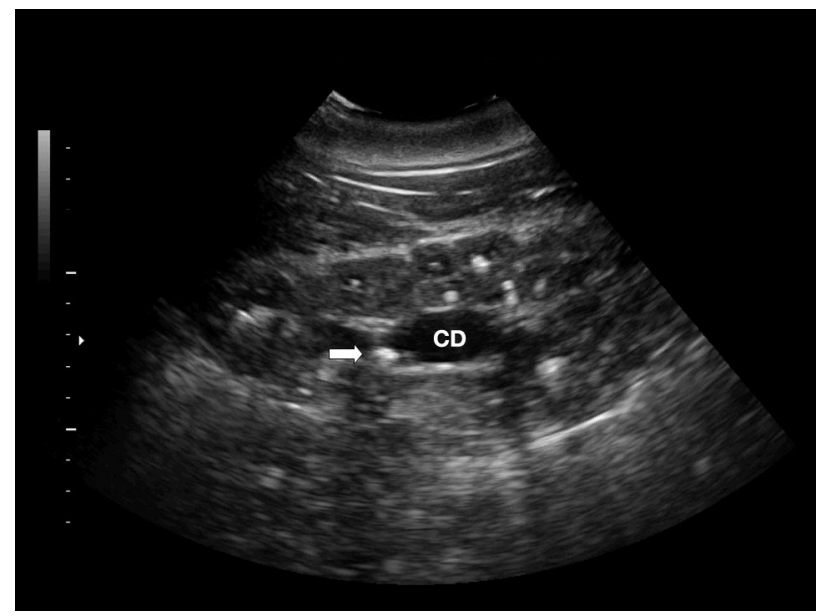

Fig. 2. Tursiops truncatus. Renal ultrasound image (Volusoni portable ultrasound machine with a 2 to $5 \mathrm{MHz} 4 \mathrm{D}$ transducer; RAB2-5-RS; General Electric Healthcare) of an advanced case of nephrolithiasis. Multiple nephroliths are visible in the kidney, as well as a dilated collecting duct (CD) and a nephrolith in the collecting duct (arrow) with acoustic shadowing controls. Both mild and advanced cases had lower mean HCT and hemoglobin compared to controls. While advanced cases were more likely to have lower red blood cell (RBC) distribution width and MCV compared to the other 2 study groups, mild cases were more likely to have higher $\mathrm{MCHC}$ and lower $\mathrm{RBC}$ counts. Controls had higher new RBC counts compare to both mild and advanced cases.

Mean platelet count was significantly higher in mild cases compared to advanced cases, and in advanced cases compared to controls. Controls had significantly higher total protein and globulins, but not albumin, compared to mild and advanced cases. Mild cases had higher serum uric acid compared to advanced cases and controls.

When testing for clinically significant differences in clinicopathologic values among the 3 study groups, both mild and advanced cases were more likely to be anemic, have high BUN, high creatinine, and low eGFR compared to controls (Table 4). Mild cases were more likely to have thrombocytosis compared to advanced cases and controls.

Renal health indicators fluctuated over the $18 \mathrm{mo}$ study period among each of the animals. Examples of fluctuations in serum BUN, creatinine, and HCT among control, mild-case, and advanced-case animals are provided in Fig. 3.

\section{Urinalyses}

Compared to mild and advanced cases, controls were more likely to have nitrite in urine and higher urine protein concentrations (Tables 5 \& 6). Advanced cases were more likely to have hematuria (urine erythrocytes and occult blood) and lower urinary pH compared to mild cases and controls. Mild cases had significantly higher uric acid concentrations in urine compared to advanced cases and controls. Of 4 advanced cases in which urinary crystals were identified, 3 animals had urinary crystals characterized as urate; the fourth advanced case had urinary crystals characterized as triple phosphate.

\section{DISCUSSION}

\section{Ammonium acid urate nephrolithiasis}

We report on a case-control study involving 14 cases of nephrolithiasis in bottlenose dolphins at the MMP with the purpose of determining the clinical relevance of this disease and assisting in diagnostic and treatment decisions. Nephrolithiasis has been reported in other marine mammal species, including a harbor seal 
Table 3. Tursiops truncatus. Comparisons of mean clinicopathologic and estimated glomerular filtration rate (eGFR) by nephrolith study group. Mild cases: 1 to 19 nephroliths, advanced cases: $\geq 20$ nephroliths. Adv: advanced cases; BUN: blood urea nitrogen; Cont: controls; ESR: erythrocyte sedimentation rate; fl: femtoliter; $\mathrm{MCH}$ : mean corpuscular hemoglobin; MCHC: mean corpuscular hemoglobin concentration; MCV: mean corpuscular volume; MPV: mean platelet volume; RBC: red blood cell

\begin{tabular}{|c|c|c|c|c|c|c|}
\hline Blood variable & $\begin{array}{l}\text { Normal reference } \\
\text { range, if } \\
\text { established }\end{array}$ & $\begin{array}{l}\text { Controls } \\
(\mathrm{n}=117)\end{array}$ & \multicolumn{2}{|c|}{$\begin{array}{cc}\text { Least-squares means } \\
\text { Mild cases } & \text { Advanced cases } \\
(\mathrm{n}=100) & (\mathrm{n}=130)\end{array}$} & $\mathrm{p}$ & $\begin{array}{c}\text { Significant } \\
\text { comparisons }\end{array}$ \\
\hline \multicolumn{7}{|l|}{ Renal health } \\
\hline $\mathrm{BUN}\left(\mathrm{mg} \mathrm{dl}^{-1}\right)$ & $34-59$ & 49 & 53 & 63 & $<0.0001$ & Cont $<$ Mild $<$ Adv \\
\hline Creatinine $\left(\mathrm{mg} \mathrm{dl}^{-1}\right)$ & $1.1-1.8$ & 1.3 & 1.3 & 1.3 & 0.39 & \\
\hline BUN:creatinine ratio & $30.9-53.6$ & 39.2 & 41.6 & 50.7 & $<0.0001$ & Adv > Cont, Mild \\
\hline \multicolumn{7}{|c|}{ Inflammation } \\
\hline White blood cells (cells $\mu l^{-1}$ ) & 1) 4895-10935 & 9203 & 7427 & 9311 & $<0.0001$ & Mild < Cont \\
\hline Neutrophils (cells $\mu l^{-1}$ ) & $2737-7570$ & 6227 & 4927 & 6141 & $<0.0001$ & Mild $<$ Adv, Cont \\
\left.\hline Lymphocytes (cells ${\mu l^{-1}}^{-1}\right)$ & $312-2731$ & 1358 & 1252 & 1300 & 0.43 & \\
\hline Monocytes $\left(\right.$ cells $\left.\mu^{-1}\right)$ & $0-576$ & 252 & 191 & 232 & 0.08 & \\
\hline Eosinophils (cells $\mu^{-1}$ ) & $100-2731$ & 1417 & 1501 & 1642 & $<0.0001$ & Cont $<$ Mild $<$ Adv \\
\hline Globulins $\left(\mathrm{g} \mathrm{dl}^{-1}\right)$ & $1.9-3.8$ & 2.8 & 2.6 & 2.5 & $<0.0001$ & Cont $>$ Mild, Adv \\
\hline Iron $\left(\mu \mathrm{g} \mathrm{dl} l^{-1}\right)$ & $92-332$ & 218 & 235 & 161 & $<0.0001$ & Adv $<$ Mild, Cont \\
\hline Alkaline phosphatase $\left(\mathrm{U} \mathrm{l}^{-1}\right)$ & $158-709$ & 340 & 374 & 323 & 0.04 & \\
\hline $60 \min \operatorname{ESR}\left(\mathrm{mm} \mathrm{h}^{-1}\right)$ & $0-19$ & 10 & 13 & 13 & 0.04 & \\
\hline \multicolumn{7}{|l|}{$\mathrm{RBC}$ production } \\
\hline Hematocrit (\%) & $38-46$ & 43 & 41 & 40 & $<0.0001$ & Cont $>$ Mild, Adv \\
\hline Hemoglobin $\left(\mathrm{g} \mathrm{dl}^{-1}\right)$ & & 14.7 & 14.4 & 14.0 & $<0.0001$ & Cont $>$ Mild, Adv \\
\hline $\operatorname{RBCs}\left(\times 10^{6} \mu^{-1}\right)$ & & 3.3 & 3.2 & 3.3 & $<0.0001$ & Mild $<$ Adv, Cont \\
\hline RBC distribution width (\%) & & 14.4 & 14.5 & 13.6 & $<0.0001$ & Adv $<$ Mild, Cont \\
\hline New RBCs $\left(100\right.$ cells $\left.^{-1}\right)$ & & 0.6 & 0.3 & 0.2 & 0.0002 & Cont $>$ Mild, Adv \\
\hline $\mathrm{MCV}(\mathrm{fl})$ & & 128 & 129 & 121 & $<0.0001$ & Adv $<$ Mild, Cont \\
\hline $\mathrm{MCH}(\mathrm{pg})$ & & 44 & 45 & 42 & $<0.0001$ & Adv $<$ Mild, Cont \\
\hline $\operatorname{MCHC}\left(\mathrm{g} \mathrm{dl}^{-1}\right)$ & & 34.6 & 35.0 & 34.6 & $<0.0001$ & Mild $>$ Adv, Cont \\
\hline Platelets (cells $\times 10^{3} \mu^{-1}$ ) & $46-173$ & 94 & 118 & 123 & $<0.0001$ & Cont $<$ Mild, Adv \\
\hline MPV (fl) & & 13.1 & 12.6 & 12.9 & 0.03 & \\
\hline Total protein $\left(\mathrm{g} \mathrm{dl}^{-1}\right)$ & $5.9-7.7$ & 7.1 & 6.9 & 6.8 & $<0.0001$ & Cont $>$ Mild, Adv \\
\hline Glucose $\left(\mathrm{mg} \mathrm{dl}^{-1}\right)$ & $80-144$ & 109 & 104 & 106 & 0.05 & \\
\hline Carbon dioxide $\left(\mathrm{mEq} \mathrm{l}^{-1}\right)$ & $17-28$ & 24.8 & 25.0 & 24.4 & 0.13 & \\
\hline Sodium $\left(\mathrm{mEq} \mathrm{l}^{-1}\right)$ & $152-159$ & 154 & 154 & 153 & 0.01 & Adv $<$ Mild, Cont \\
\hline Chloride (mEq $\left.\mathrm{l}^{-1}\right)$ & $115-125$ & 118 & 118 & 119 & 0.02 & \\
\hline Potassium (mEq $\mathrm{l}^{-1}$ ) & $3.4-4.1$ & 3.8 & 3.8 & 3.8 & 0.53 & \\
\hline Uric acid $\left(\mathrm{mg} \mathrm{dl}^{-1}\right)$ & $0.0-0.7$ & 0.17 & 0.29 & 0.15 & 0.0008 & Mild $>$ Adv, Cont \\
\hline Albumin $\left(\mathrm{g} \mathrm{dl}^{-1}\right)$ & $3.8-4.9$ & 4.4 & 4.3 & 4.3 & 0.43 & \\
\hline eGFR $\left(\mathrm{ml} \mathrm{min} \mathrm{min}^{-1} 2.78 \mathrm{~m}^{-2}\right)$ & $>150$ & 230 & 234 & 234 & 0.81 & \\
\hline
\end{tabular}

Table 4. Tursiops truncatus. Comparisons of percent high or low clinicopathologic values by nephrolith study group. Definitions are based upon previously established normal reference ranges for this animal population (Venn-Watson et al. 2007, 2008). Mild cases: 1 to 19 nephroliths, advanced cases: $\geq 20$ nephroliths. BUN: blood urea nitrogen; eGFR: estimated glomerular filtration rate; ESR: erythrocyte sedimentation rate; HCT: hematocrit

\begin{tabular}{|c|c|c|c|c|c|}
\hline Descriptor & Definition & $\begin{array}{c}\text { No. }(\%) \\
\text { control samples } \\
(\mathrm{n}=116)\end{array}$ & $\begin{array}{l}\text { No. }(\%) \\
\text { mild cases } \\
(\mathrm{n}=99)\end{array}$ & $\begin{array}{c}\text { No. }(\%) \\
\text { advanced cases } \\
(\mathrm{n}=128)\end{array}$ & $\mathrm{p}$ \\
\hline Anemia & $\mathrm{HCT}<38 \%$ & $1(0.9)$ & $16(16.2)$ & $17(13.3)$ & $<0.0001$ \\
\hline Thrombocytosis & Platelets > 140000 cells $\mu^{-1}$ & $18(15.5)$ & $32(32.3)$ & $31(26.6)$ & 0.01 \\
\hline Lymphopenia & Lymphocytes $<300$ cells $\mathrm{l}^{-1}$ & $3(2.6)$ & $0(0)$ & $3(2.3)$ & 0.13 \\
\hline High BUN & BUN $>59 \mathrm{mg} \mathrm{dl}^{-1}$ & $10(8.6)$ & $15(15.20$ & $73(56.6)$ & $<0.0001$ \\
\hline High creatinine & Creatinine $>1.9 \mathrm{mg} \mathrm{dl}^{-1}$ & $1(0.9)$ & $12(12.1)$ & $7(5.4)$ & 0.001 \\
\hline Hyponaturia & Sodium $<152 \mathrm{mEq}^{-1}$ & $13(11.2)$ & $10(10.1)$ & $19(14.7)$ & 0.53 \\
\hline Hyperchloremia & Chloride $>125 \mathrm{mEq} \mathrm{l}^{-1}$ & $1(0.9)$ & $0(0)$ & $1(0.8)$ & 0.50 \\
\hline Hypoglobulinemia & Globulins $<2.0 \mathrm{~g} \mathrm{dl}^{-1}$ & $5(5.2)$ & $0(0)$ & $5(3.9)$ & 0.02 \\
\hline Low iron & Iron $<100 \mu \mathrm{g} \mathrm{dl}^{-1}$ & $3(2.6)$ & $4(4.0)$ & $11(8.5)$ & 0.10 \\
\hline Elevated ESR & $\mathrm{ESR}>20 \mathrm{~mm} \mathrm{~h}^{-1}$ & $14(12.7)$ & $13(13.7)$ & $19(15.1)$ & 0.87 \\
\hline Low eGFR $(<150)$ & eGFR $<150 \mathrm{ml} \mathrm{min}^{-1} 2.78 \mathrm{~m}^{-2}$ & $1(0.9)$ & $12(12.1)$ & $7(5.4)$ & 0.001 \\
\hline
\end{tabular}



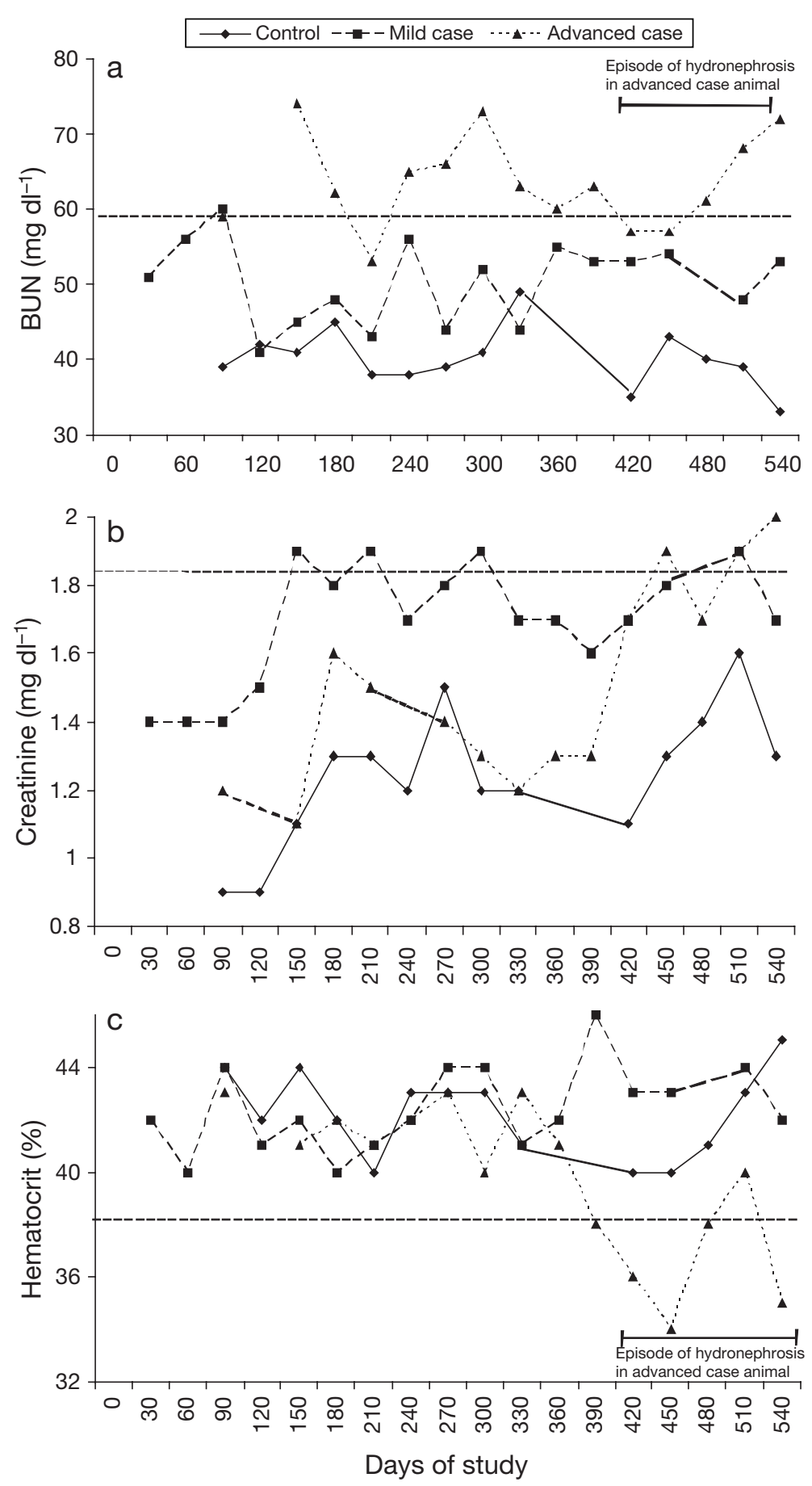

Fig. 3. Tursiops truncatus. Eighteen month time series of serum (a) blood urea nitrogen (BUN), (b) creatinine, and (c) hematocrit in a control, a mild case of nephrolithiasis, and an advanced case. Horizontal dashed line: normal level of BUN/creatinine/hematocrit

(Stroud 1979), northern elephant seal, California sea lion (Dennison et al. 2007), and 2 West Indian manatees (Keller et al. 2008); the northern elephant seal and California sea lion had urate nephrolithiasis. We previously reported a case of urate nephrolithiasis associ- ated with end-stage renal disease in an adult bottlenose dolphin (Venn-Watson et al. 2008).

Urate nephrolithiasis is caused by uric acid, sodium acid urate, or ammonium acid urate calculi. In the present study, all nephroliths tested postmortem from MMP non-study bottlenose dolphins were characterized as being $100 \%$ ammonium acid urate. It is assumed, therefore, that the primary type of nephrolithiasis diagnosed by ultrasound in our dolphin population is ammonium acid urate.

We report significantly lower urinary $\mathrm{pH}$ among advanced cases $(\mathrm{pH}=6.0)$ compared to mild cases and controls $(\mathrm{pH}=6.4$ and 6.3, respectively). The foremost risk factor for urate nephrolithiasis, specifically uric acid nephrolithiasis, in terrestrial animals is acidic urine $(\mathrm{pH}<5.5)$ (Shekarriz \& Stoller 2002). While the present study did associate lower urinary $\mathrm{pH}$ with advanced cases, it also demonstrated that urate nephrolithiasis may be present in dolphins with urine $\mathrm{pH}>5.5$ and that urinary $\mathrm{pH}$ did not differ among mild-nephrolith-formers compared to non-nephrolith-formers. These findings are consistent with ammonium acid urate nephroliths, which can form in acidic, neutral, and even slightly alkaline urine (Berenyi 1972, Klohn et al. 2004). Further research is needed to better understand whether lower urinary $\mathrm{pH}$ causes advanced cases, or if the presence of more nephroliths lowers urinary $\mathrm{pH}$. Additionally, if low urinary $\mathrm{pH}$ is not the primary cause of urate nephrolithiasis in dolphins, use of alkalinizing treatments may be limited in preventing or treating mild cases.

High-purine diets have been associated with urate nephrolithiasis (Ekeruo et al. 2004). In most mammals, ingested proteins (purines) are converted to xanthine, which is subsequently converted to hypoxanthine, xanthine oxidase, uric acid, and, finally, allantoin, which is excreted by the kidneys. Exceptions to this purine metabolic pathway include humans and other higher primates, dalmations, birds, reptiles, and desert mammals, all of which lack the enzyme uricase (Vogels \& Van Der Drift 1976). For these animals, the final product of purine metabolism is uric acid, which can predispose animals to urate nephrolithiasis. While a review of the literature did not confirm how dolphins metabolize purines, dolphins 
Table 5. Tursiops truncatus. Comparisons of urinalysis results (categorical variables) by nephrolith study group. Mild cases: 1 to 19 nephroliths; advanced cases: $\geq 20$ nephroliths

\begin{tabular}{|c|c|c|c|c|}
\hline Descriptor & $\begin{array}{c}\text { No. }(\%) \\
\text { control samples } \\
(\mathrm{n}=49)\end{array}$ & $\begin{array}{l}\text { No. }(\%) \\
\text { mild cases } \\
(\mathrm{n}=67)\end{array}$ & $\begin{array}{c}\text { No. }(\%) \\
\text { advanced cases } \\
(\mathrm{n}=96)\end{array}$ & $\mathrm{p}$ \\
\hline Glucose-positive & 8/49 (16.3) & 12/67 (17.9) & 18/96 (18.8) & 0.80 \\
\hline Ketones - positive & $2 / 47(4.3)$ & $0 / 67(0)$ & 2/96 (2.1) & 0.47 \\
\hline Nitrite - positive & $16 / 49(32.7)$ & $0(0)$ & $0(0)$ & $<0.0001$ \\
\hline Leukocytes - positive & 23/49 (46.9) & 23/67 (34.3) & $40 / 96(41.7)$ & 0.006 \\
\hline Erythrocytes - positive & $11 / 25(44.0)$ & $7 / 40(17.5)$ & $53 / 55(96.4)$ & $<0.0001$ \\
\hline Clarity_-cloudy & $10 / 28(35.7)$ & $1 / 45(2.2)$ & 26/67 (38.8) & $<0.0001$ \\
\hline Appearance - abnormal & $5 / 20(25)$ & $1 / 40(2.5)$ & 9/63 (14.3) & 0.02 \\
\hline Occult blood — positive & $15 / 48(31.3)$ & $3 / 65(4.6)$ & $61 / 94$ (64.9) & $<0.0001$ \\
\hline Bacteria - positive & $6 / 25(24)$ & $3 / 40(7.5)$ & $7 / 48(14.6)$ & 0.36 \\
\hline Crystals - positive & $3^{\mathrm{a}} / 25(12)$ & $2^{\mathrm{b}} / 40(5)$ & 6/55 (10.9) & 0.14 \\
\hline Hyaline casts - positive & $3 / 49(6.1)$ & $3 / 70(4.3)$ & $8 / 98(8.2)$ & 0.59 \\
\hline
\end{tabular}

Table 6. Tursiops truncatus. Comparisons of urine values (continuous variables) by nephrolith study group. Mild cases: 1 to 19 nephroliths; advanced cases: $\geq 20$ nephroliths. Adv: advanced cases; Cont: controls

\begin{tabular}{|c|c|c|c|c|c|}
\hline Urine variable & $\begin{array}{l}\text { Control samples } \\
\qquad(\mathrm{n}=49)\end{array}$ & $\begin{array}{l}\text { Mild cases } \\
(\mathrm{n}=67)\end{array}$ & $\begin{array}{l}\text { Advanced cases } \\
(\mathrm{n}=96)\end{array}$ & $\mathrm{p}$ & $\begin{array}{l}\text { Significant group } \\
\text { comparisons }\end{array}$ \\
\hline $\mathrm{pH}$ & 6.3 & 6.4 & 6.1 & 0.007 & Adv $<$ Cont, Mild \\
\hline Specific gravity & 1.026 & 1.026 & 1.028 & 0.33 & \\
\hline Creatinine $\left(\mathrm{mg} \mathrm{dl}^{-1}\right)$ & 97 & 76 & 104 & 0.04 & \\
\hline Protein (mg mg ${ }^{-1}$ creatinine) & 1025 & 141 & 333 & $<0.0001$ & Cont $>$ Mild, Adv \\
\hline Uric acid (mg mg ${ }^{-1}$ creatinine) & 118 & 294 & 69 & $<0.0001$ & Mild > Adv, Cont \\
\hline
\end{tabular}

have osmoregulation capabilities resembling that of some desert mammals, and as such, may have similar means of conserving water and metabolizing purines (Ortiz 2001). It is also possible that cetaceans have evolved their own process for breaking down purines, independent of the 2 traditional mammalian models, as has been recently reported in marsupials and monotremes (Keebaugh \& Thomas 2009). There is a need to study purine metabolism, including the presence or absence of uricase in dolphins.

Ammonium urate nephrolithiasis in terrestrial mammals has been associated with infections by urealytic bacteria, low dietary and urinary phosphate, low fluid intake, and portosystemic shunts (Osborne et al. 1995, Klohn et al. 2004). The controls in the present study were significantly more likely to have urinary nitrite, an indicator of bacteria, compared to cases; further, controls had the highest prevalence of urinary bacteria. These findings do not support the conclusion that urinary tract infection or nephritis is the primary cause of urate nephrolithiasis in our population. Further, the overwhelming majority of urine samples in the present study were collected by free catch, and the presence of contaminant bacteria in urine not collected by catheterization is not unusual. There were no instances, among case or control animals in the present study, when the presence of bacteria in urine was interpreted as a primary bacterial urinary-tract infection. To better characterize true bacterial urinary-tract infections among this animal population, urine samples would need to be collected consistently with a catheter. Cases and controls were fed similar diets of capelin, herring, mackerel, and squid, decreasing the chance that dietary differences were present among animals in our population. Finally, animals in the present study population are not known to have portosystemic shunts, and cases were not immediately related to each other; due to the high prevalence of nephrolithiasis in our population, it is unlikely that nephrolithiasis is caused by portsystemic shunts. There have been no formal evaluations, however, for portosystemic shunts in dolphins. Additional studies are needed to better assess poten- 
tial associations of bacterial infections, low dietary phosphate, low fluid intake, and portosystemic shunts with ammonium urate nephrolithiasis in dolphins.

Mild cases were more likely to have higher serum and urinary uric acid compared to controls. While the cause of this finding and its clinical significance are unknown, higher serum and urine uric acid levels in mild cases may reflect a trigger for urate stone formation in the early stages of disease that is not present in advanced cases.

Urate nephrolithiasis, especially uric acid nephrolithiasis, in other mammals has been associated with hyperuricemia and hyperuricosuria (Ngo \& Assimos 2007). An exception is pure urate nephrolithiasis associated with insulin resistance in humans (Abate et al. 2004, Daudon et al. 2006); in these patients, pure urate stone formation occurs in the face of normal urine uricacid levels and low serum uric-acid levels. Normouricosuric uric-acid nephrolith-formers appear to have a renal acidification disease likely linked to an insulinresistant state (Sakhaee et al. 2002). We previously reported that healthy, fasting dolphins have a diabetes-like metabolism, including a sustained hyperglycemia, and have proposed the bottlenose dolphin as a potential animal model for type 2 diabetes (VennWatson \& Ridgway 2007). In the present study, all of the advanced cases and half of the mild cases had bilateral nephrolithiasis, providing additional support that an underlying metabolic cause versus a renalbased etiology may be present. What appears to be inconsistent between the metabolic syndrome-associated urate nephrolithiasis in humans and urate nephrolithiasis in dolphins is the subtype of nephroliths; humans appear to develop uric acid nephroliths while dolphins develop ammonium acid urate nephroliths. The difference in nephrolith type between dolphins and humans may be due to differences in purine metabolites and an enhanced contribution of ammonium in dolphins. Alternatively and interestingly, the same archived nephroliths submitted for analysis in the present study were previously characterized as uric acid by another laboratory using a less sophisticated method; thus, there may be a need to confirm that humans are not also developing ammonium acid urate versus uric acid nephroliths. Given the common predisposition of people with type 2 diabetes and dolphins for urate nephrolithiasis, additional research is needed to study additional links among primates, cetaceans, and metabolic disease.

\section{Clinical significance of nephrolithiasis in dolphins}

BUN is a measurement of urea in the blood, and urea is produced by the liver and excreted by the kidney as a breakdown product of ingested protein. Due to very high protein diets of dolphins, normal BUN levels (36 to $59 \mathrm{mg} \mathrm{dl}^{-1}$ ) are expected to be higher than in humans and other omnivorous mammals (human normal reference range, 7 to $21 \mathrm{mg} \mathrm{dl}^{-1}$ ) (Rao et al. 2007). Case dolphins in the present study, however, were more likely to have BUN levels > $59 \mathrm{mg} \mathrm{dl}^{-1}$ compared to controls. While these results are indicative of clinically relevant renal disease among those with nephrolithiasis, BUN levels in other mammals may increase due to non-renal causes, including heart failure, dehydration, gastrointestinal ulcers, and changes in protein content of diet (Pagana \& Pagana 2006); as such, increased serum creatinine and decreased GFR are better indicators of reduced kidney function.

Creatinine is a breakdown product of muscle, is produced at a constant rate, and is filtered by the kidneys with no reabsorption, making it a reliable indicator of renal function (Perrone et al. 1992). Serum creatininebased eGFR are routinely used in human medicine (Levey et al. 2006), and a previously established dolphin-adjusted eGFR equation (Venn-Watson et al. 2008) was applied in the present study. While there were no significant differences in mean serum creatinine levels among cases and controls, both mild and advanced cases were significantly more likely to have clinically high levels of creatinine $\left(>1.9 \mathrm{mg} \mathrm{dl}^{-1}\right)$ and low eGFR (<150 ml min $\left.\mathrm{mi}^{-1} 2.78 \mathrm{~m}^{-2}\right)$ compared to controls. Given the higher prevalence of clinically high serum BUN and creatinine levels and low eGFR in cases compared to controls, we conclude that the presence of nephroliths can negatively impact renal function in bottlenose dolphins.

Nephrolithiasis cases in the present study were more likely to have anemia (HCT < 38\%) compared to controls. Anemia, specifically microcytic, normochromic anemia, is a common abnormality in other mammals with chronic renal disease due to decreased renal production of erythropoietin, which stimulates bone marrow production of RBCs (Zuckerman 2007). While both mild and advanced cases had higher prevalence of anemia compared to controls, the profiles of anemia between the 2 case groups differed. Mild cases had the lowest RBC count and highest MCHC compared to advanced cases and controls, and advanced cases had the lowest $\mathrm{MCV}, \mathrm{MCH}$, and hemoglobin compared to the other 2 study groups. These differences may be attributed to differing or additive causes of anemia in the 2 case groups, namely decreased erythropoietin and blood loss evidenced by hematuria among our advanced cases.

In the present study, mild cases had lower mean WBCs, specifically neutrophils, compared to advanced cases and controls. This finding may reflect the higher prevalence of bacteria in urine among the control and 
advanced case animals (24 and $14.6 \%$ of urine samples, respectively) compared to the mild cases ( $7.4 \%$ of urine samples). These differences in bacteria-positive urine samples were not statistically significant, however, and most of the samples were susceptible to contamination via free catch.

Lacking in our case animals was a significant change in specific gravity, which is expected to change in other species with advanced renal disease. Dolphins are very good osmoregulators and have a reniculate renal morphology (Ortiz 2001). Given the challenge of living in a saline environment without access to fresh water, dolphins and other marine mammals may have a highly adaptable renal physiology that limits the use of specific gravity for clinical purposes until they near end-stage renal disease.

Study limitations include the use of ultrasonographic diagnosis of renal nephrolithiasis, in which the number of nephroliths counted is less reliable than using CT scanning (Fowler et al. 2002). Three $(21 \%)$ case dolphins also had renal CT scans, however, and results were comparable with ultrasound analysis in those animals. Case definitions were dependent upon nephrolith counts, and nephrolith sizes varied from $3 \mathrm{~mm}$ to $>2 \mathrm{~cm}$. An alternate means of defining cases and controls may have been volume of nephroliths relative to kidney size, but a reliable measuring tool was not readily accessible for the present study. In most of the dolphins, case animals were diagnosed with nephrolithiasis before the study period (January 2006 to June 2007); as part of the MMP's treatment plan for dolphins with nephrolithiasis, 6 (43\%) case animals were on hydration therapy (1 to 41 tube-fed fresh water $\mathrm{d}^{-1}$ ), and varying animals were on varying treatments, including $2(14 \%)$ cases on allopurinol (900 to $2100 \mathrm{mg}$ orally twice a day), $3(21 \%)$ cases on potassium citrate (30 to $100 \mathrm{mEq}$ orally twice $\mathrm{d}^{-1}$ ), and 2 (14\%) cases on sodium bicarbonate (2600 to $3250 \mathrm{mg}$ orally 3 to 4 times $\mathrm{d}^{-1}$ ). Hydration therapy, uric acid formation inhibitors, and urine alkalinizers may have influenced blood and urine values, masking differences between cases and controls. A preliminary assessment among cases over $2 \mathrm{yr}$, however, has not yielded any evidence that these medications have significantly impacted serum uric acid, urine uric acid, or urine $\mathrm{pH}$ over time; and treatment with allopurinol has been discontinued while we investigate whether administering allopurinol with a naturally purine-rich fish diet could lead to xanthine nephrolith formation. Finally, given the high prevalence of nephrolithiasis and possible presence of predisposing risk factors among all animals in the study population, the value of comparisons between cases and controls may be limited. Similar comparisons of blood and urine variables between this population and wild dolphins may pro- vide valuable insight into the risk factors for and etiology of nephrolithiasis.

Nephroliths in marine mammals can lead to ureteral and urethral obstruction, hydronephrosis, kidney atrophy, and loss of function (Dennison et al. 2007, Keller et al. 2008, Venn-Watson et al. 2008), as was also evident in the present study's population of dolphins. As such, the MMP is striving to treat and prevent nephrolithiasis in dolphins. Invasive treatments used in humans, including lithotripsy, have been considered but are logistically problematic. Urine alkalinizers to date have not appeared to have changed urine $\mathrm{pH}$ or nephrolith presence in case dolphins. Currently, case animals are provided 1 to 31 fresh water $\mathrm{d}^{-1}$, and ongoing studies are investigating the potential role of diet and associated metabolic responses in preventing or facilitating ammonium urate stone formation.

In conclusion, ammonium acid urate nephrolithiasis is present in bottlenose dolphins.

Among dolphins with nephroliths visualized by ultrasound, this disease appears to be clinically relevant, impacting both renal function and erythropoietin production. While the cause of ammonium acid urate nephrolithiasis in dolphins is unknown, the lack of hyperuricosuria and hyperuremia in case animals, along with a high prevalence of bilateral disease, may indicate that a metabolic syndrome is present. Better understanding of purine metabolism in dolphins is needed to target prevention and treatment of nephrolithiasis in dolphins.

Acknowledgements. We thank the reviewers for their valued time, patience, and contributions that improved the quality and impact of this manuscript. This work was funded by the Office of Naval Research's In-house Laboratory Independent Research (ILIR) program.

\section{LITERATURE CITED}

Abate N, Chandalia M, Cabo-Chan AV, Moe OW, Sakahaee K (2004) The metabolic syndrome and uric acid nephrolithiasis: novel features of renal manifestation of insulin resistance. Kidney Int 65:386-392

$>$ Berenyi M (1972) Models for the formation of uric acid and urate stones. Int Urol Nephrol 4:199-204

> Daudon M, Traxer O, Conort P, Lacour B, Jungers P (2006) Type 2 diabetes increases the risk for uric acid stones. J Am Soc Nephrol 17:2026-2033

> Dennison S, Gulland F, Haulena M, Morais HE, Colgrove K (2007) Urate nephrolithiasis in a Northern elephant seal (Mirounga angustirostris) and a California sea lion (Zalophus californianus). J Zoo Wildl Med 38:114-120

Dold C, Ridgway S (2007) Cetaceans. In: West G, Heard DJ, Caulkett N (eds) Zoo animal and wildlife immobilization and anesthesia. Blackwell Publishers, Ames, IA, p 485-496

Ekeruo W, Tan Y, Young M, Dahm P and others (2004) Metabolic risk factors and the impact of medical therapy on the management of nephrolithiasis in obese patients. J Urol 172:159-163 
Fowler KAB, Locken JA, Duchesne JH, Williamson MR (2002) US for detecting renal calculi with nonenhanced CT as a reference standard. Radiology 222:109-113

Grove RA, Bildfell R, Henny CJ, Buhler DR (2003) Bilateral uric acid nephrolithiasis and ureteral hypertrophy in a free-ranging river otter (Lontra canadensis). J Wildl Dis 39:914-917

Keebaugh AC, Thomas JW (2009) The genomes of the South American opossum (Monodelphin domestica) and platypus (Ornithorhynchus anatinus) encode a more complete purine catabolic pathway than placental mammals. Comp Biochem Physiol D 4:174-178

Keller M, Moliner JL, Vasquez G, Cruz D and others (2008) Nephrolithiasis and pyelonephritis in two West Indian manatees (Trichechus manatus spp.). J Wildl Dis 44: 707-711

Klohn M, Bolle JF, Reverdin NP, Susini A, Baud A, Graber P (2004) Ammonium urate urinary stones. Urol Res 14: $315-318$

> Levey AS, Coresh J, Greene T, Stevens LA and others (2006) Using standardized serum creatinine values in the modification of diet in renal disease study equation for estimating glomerular filtration rate. Ann Intern Med 145: $247-254$

> Moe O (2006) Kidney stones: pathophysiology and medical management. Lancet 367:333-344

> Ngo TC, Assimos DG (2007) Uric acid nephrolithiasis: recent progress and future directions. Rev Urol 9:17-27

> Ortiz RM (2001) Osmoregulation in marine mammals. J Exp Biol 204:1831-1844

Osborne CA, Lulich JP, Bartges JW, Unger LK and others (1995) Canine and feline urolithiasis: relationship of etiopathogenesis to treatment and prevention. In: Osborne CA, Finco DR (eds) Canine and feline urology. Williams \& Wilkins, Baltimore, MD, p 798-888

Editorial responsibility: Michael Moore, Woods Hole, Massachusetts, USA
Pagana KD, Pagana TJ (2006) Mosby's manual of diagnostic and laboratory tests, 3rd edn. Mosby, St. Louis, MO

- Perrone RD, Madias NE, Levey AS (1992) Serum creatinine as an index of renal function: new insights into old concepts. Clin Chem 38:1933-1953

Rao DA, Le T, Bhushan V (2007) First aid for the USMLE step 1 2008. McGraw-Hill Medical, New York

Sakhaee K, Adams-Huet B, Moe OW, Pak CYC (2002) Pathophysiologic basis for normouricosuric uric acid nephrolithiasis. Kidney Int 62:971-979

Shekarriz B, Stoller ML (2002) Uric acid nephrolithiasis: current concepts and controversies. J Urol 168:1307-1314

Stroud RK (1979) Nephrolithiasis in a harbor seal. J Am Vet Med Assoc 175:924-925

- Ulrich LK, Bird K, Koehler L, Swanson L (1996) Urolith analysis: submission, methods, and interpretation. Vet Clin North Am Small Anim Pract 26:393-400

> Venn-Watson S, Ridgway S (2007) Big brains and blood glucose: common ground for diabetes mellitus in humans and dolphins. Comp Med 57:241-246

Venn-Watson S, Jensen ED, Ridgway SH (2007) Effects of age and sex on clinicopathologic reference ranges in a healthy managed Atlantic bottlenose dolphin population. J Am Vet Med Assoc 231:596-601

> Venn-Watson S, Smith CR, Dold C, Ridgway SH (2008) Use of a serum-based glomerular filtration rate prediction equation to assess renal function by age, sex, fasting, and health status in bottlenose dolphins (Tursiops truncatus). Mar Mamm Sci 24:71-80

> Vogels GD, Van Der Drift C (1976) Degradation of purines and pyrimidines by microorganisms. Bacteriol Rev 40: 403-468

Zuckerman K (2007) Approach to the anemias. In: Goldman L, Ausiello D (eds) Cecil medicine, 23rd edn. Saunders Elsevier, Philadelphia, PA, p 1179-1186

Submitted: August 12, 2009; Accepted: December 1, 2009 Proofs received from author(s): March 1, 2010 